\title{
Optical, Photoelectrochemical, and Electrochemical Impedance Studies on Photoactive Organic/Inorganic/Interface Assemblies of Poly 2,2 Bithiophene/Poly 3-(2-Thienyl) Aniline (PThA)/ $\mathrm{TiO}_{2}$
}

\author{
Kasem K. Kasem ${ }^{1}$, Houria Sadou' ${ }^{2}$, Henry Worley ${ }^{1}$, Jordan Wenger ${ }^{1}$ \\ ${ }^{1}$ School of Sciences, Indiana University Kokomo, Kokomo, IN, USA \\ ${ }^{2}$ Laboratoire de Chimie des Matériaux Inorganiques et Applications, University of Sciences and Technology of Oran-Mohamed \\ Boudiaf, Oran, Algeria \\ Email: *kkasem@iuk.edu
}

How to cite this paper: Kasem, K.K., Sadou, H., Worley, H. and Wegner, J. (2018) Optical, Photoelectrochemical, and Electrochemical Impedance Studies on Photoactive Organic/Inorganic/Interface Assemblies of Poly 2,2 Bithiophene/Poly 3-(2-Thienyl) Aniline (PThA)/TiO ${ }_{2}$. Journal of Materials Science and Chemical Engineering, 6, 50-67. https://doi.org/10.4236/msce.2018.68005

Received: July 11, 2018

Accepted: August 28, 2018

Published: August 31, 2018

Copyright (c) 2018 by authors and Scientific Research Publishing Inc. This work is licensed under the Creative Commons Attribution International License (CC BY 4.0).

http://creativecommons.org/licenses/by/4.0/

\section{(c) (†) Open Access}

\begin{abstract}
Particles of $\mathrm{TiO}_{2}$ modified with poly 3-(2-thienyl) aniline (PThA) and occluded in poly 2,2 bithiophene (PBTh), were subjected to optical, electrochemical impedance spectroscopic (EIS) and photoelectrochemical (PEC) investigation in aqueous, acetate, citrate, and phosphate electrolytes. EIS studies revealed that the assembly film of $\mathrm{TiO}_{2} / \mathrm{PThA} / \mathrm{PBTh}$ possess porous-type structure. They also confirmed the approximate value of $\mathrm{E}_{\mathrm{f}}$ obtained from electrochemical studies. Both EIS and optical studies indicated that ac conductivity is much greater than dc conductivity. Guided by the properties of PBTh, no large changes in the energy band structure occurred due to occlusion of $\mathrm{TiO}_{2}$ in $\mathrm{PBTh}$ films. Occlusion of $\mathrm{TiO}_{2} / \mathrm{PThA}$ into the network structure of $\mathrm{PBTh}$ inhibits the energy dissipation process and impeded charge polarization process of the material. Photoelectrochemical outcome suggested possible band alignments between the organic film and $\mathrm{TiO}_{2}$ and formation of hybrid sub-bands. Inclusion of $\mathrm{TiO}_{2}$ in the thiophene-based polymers enhanced the charge separation and consequently charge transfer processes and widen the absorption in visible light range.
\end{abstract}

\section{Keywords}

$\mathrm{TiO}_{2}$, Organic Polymers, Photoactive Interfaces, Optical, Organic Semiconductors and Impedance Spectroscopy 


\section{Introduction}

An important method for creation or elimination of defects in solid materials is surface or bulk modification of inorganic/organic interfaces. This method will also alter the donor/acceptor character of these interfaces. The charge production, separation, and transfer at these interfaces were the subject of several investigations. Hybrid interfaces, such as those at the hetero-junction of inorganic/organic interfaces (IOI) recently became the focus of several research efforts [1]-[6].

Because of its chemical stability, $\mathrm{TiO}_{2}$ was subjected to many investigations compared to other photoactive metal oxides. $\mathrm{TiO}_{2}$-based heterojunction assemblies were included in several applications [7]-[20]. Enhancing the photoelectrical performance of a dye-sensitized solar cell was achieved by doping $\mathrm{SrTiO}_{3}$ : $\mathrm{Sm}^{3+} / \mathrm{SiO}_{2}$ core-shell nanoparticles in the cell's photoanode [7] [17]. Several applications used $\mathrm{TiO}_{2}$-based interfaces for water splitting and hydrogen production [8] [15], photocatalysis [9] [13], and solar cells [12]. Involving $\mathrm{TiO}_{2}$ in photoactive self-cleaning polymer coatings was also recently reported [14] [20].

Occlusion electrodeposition (OE) is one of the most effective methods for building photoactive assemblies of hybrid thin film interfaces. $\mathrm{OE}$ has been used to build composite films containing occluded $\mathrm{TiO}_{2}$ [21] [22] [23] [24] or CdS [25] [26] particles within other matrices.

In this article, we investigated difference(s) in optical, electrical properties, and photoelectrochemical behaviors caused by the occlusion of $\mathrm{TiO}_{2}$ surface modified with PThA in organic polymers Poly Bithiophene (PBTh). In particular, we studied the changes in the photocurrent generation as an indicator for this assembly's ability to cause the photoinduced charge separation. Further electrochemical impedance spectroscopy (EIS) studies were used to investigate changes in electrical properties, such as dielectric constants and electrical conductivity. The host matrix was produced by electro-polymerization of 2,2 bithiophene (BTh) which forms polymeric networks suitable for efficient occlusion. The optical parameters such as the optical conductivity $\left(\sigma_{\text {opt }}\right)$, optical absorption coefficient $(\alpha)$, refractive index $(n)$, real dielectric constants $\left(\varepsilon_{r}\right)$, and imaginary dielectric constants $\left(\varepsilon_{i}\right)$ were also investigated.

\section{Experimental}

\subsection{Reagents}

The monomers 2,2 bithiophene (BTh), and 3-(2-thienyl) aniline (ThA) (Alfa Aesar) were used to prepare their corresponding polymers; poly 2,2 bithiophene (PBTh) and poly 3-(2-thienyl) aniline (PThA), respectively. All of the chemicals used were of analytical grade and used as received from the vendors. Unless otherwise stated all of the solutions were prepared using deionized (DI) water.

\subsection{Preparations}

Surface modified $\mathrm{TiO}_{2}$ nanoparticles were prepared as previously described [27], 
briefly; suspensions of $\mathrm{TiO}_{2} / \mathrm{P} 2 \mathrm{ThA}$ interface were prepared as follows: $0.05 \mathrm{~g}$ of $\mathrm{TiO}_{2}$ nanoparticles were suspended in the solution of $2 \mathrm{ThA}$ in acetonitrile. The mixture was subjected to a 10 minute sonication followed by stirring for 1.0 hour to allow maximum adsorption of $2 \mathrm{ThA}$ on the $\mathrm{TiO}_{2}$ nanoparticles. The excess $2 \mathrm{ThA}$ was removed by centrifugation. The IOI thin films were prepared using occlusion method; thin films of $\mathrm{TiO}_{2}$ modified with PTHA/PBTh were generated electrochemically using cyclic voltammetry (CV) by repetitive cycling of the FTO electrode potential between -0.5 and $1.7 \mathrm{~V}$ vs $\mathrm{Ag} / \mathrm{AgCl}$ in an acetonitrile suspension $(1 \mathrm{mg} / \mathrm{mL})$ of $\mathrm{TiO}_{2}, 1 \mathrm{mM}$ of the $\mathrm{BTh}$ monomer, and $0.5 \mathrm{M} \mathrm{LiClO}_{4}$.

\subsection{Instrumentation}

A conventional three-electrode cell consisting of a Pt wire as a counter electrode, a $\mathrm{Ag} / \mathrm{AgCl}$ reference electrode, and FTO with surface area $2.0 \mathrm{~cm}^{2}$ as working electrode was used for electrochemical studies. Photoelectrochemical studies on the thin solid films were performed on the experimental setup as described in previous work [27]. A Solartron 2101A was used for EIS studies. A BAS 100W electrochemical analyzer (Bioanalytical Co.) was used to perform the electrochemical studies. Optical parameters were calculated based on the steady state reflectance spectra, measured by a Shimadzu UV-2101PC spectrophotometer. An Olympus BX-FL reflected light fluorescence microscope, working with polarized light at wavelengths ranging between 330 and $550 \mathrm{~nm}$ was used to visualize the surface imaging of the film. Irradiation was performed with a solar simulator 300-watt xenon lamp (Newport, NJ) with an IR filter. All measurements were performed at $298 \mathrm{~K}$.

\section{Results and Discussion}

\subsection{Optical Studies}

Optical parameters such as $\sigma_{\text {opo }} \alpha$, skin factor, $n, \varepsilon_{r}$ and $\varepsilon_{i}$ have been calculated and plotted as a function of photon energy. The results are displayed in Figures 1-5.

\subsubsection{Optical Band Gap Studies}

The absorption spectra of the $\mathrm{TiO}_{2} / \mathrm{PThA} / \mathrm{PBTh}$ assembly displayed in Figure 1 (A) indicates that occlusion of $\mathrm{TiO}_{2}$ shifts the absorption peak to higher photon energies than that of the host polymer PBTh. Figure 1(B) and Figure 1(C) were prepared after treatment of the absorption data as plots of $\alpha 1 / 2$ vs photon energy $(h v)$ and $\left(a^{\star} h v\right)^{2}$ vs $h v$, respectively, as described in previous study [28]. The value of $\alpha$ was calculated using a film thickness of $1.0 \mu \mathrm{m}$. Figure 1(B) and Figure $1(\mathrm{C})$ indicated that the absorption behavior of the host film was dominating the assembly behavior. Both the host polymer, PBTh, and the assembly showed direct and indirect band gaps. This is because the occlusion of $\mathrm{TiO}_{2}$, modified with PThA, created hybrid sub-bands with smaller band gaps between the highest occupied molecular orbitals (HOMO) and lowest unoccupied molecular 


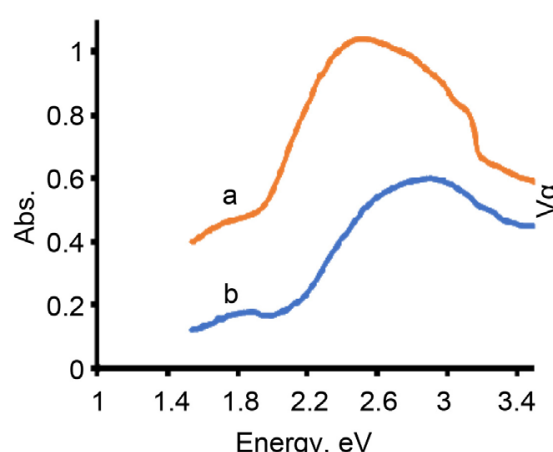

(A)

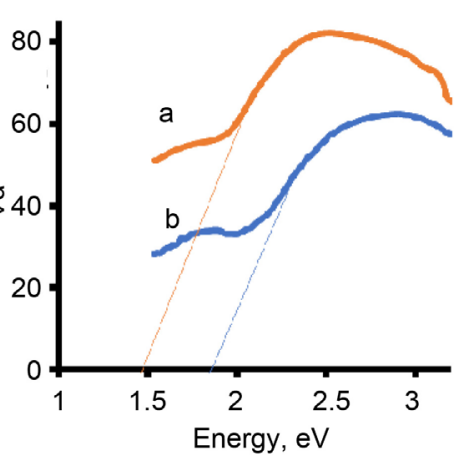

(B)

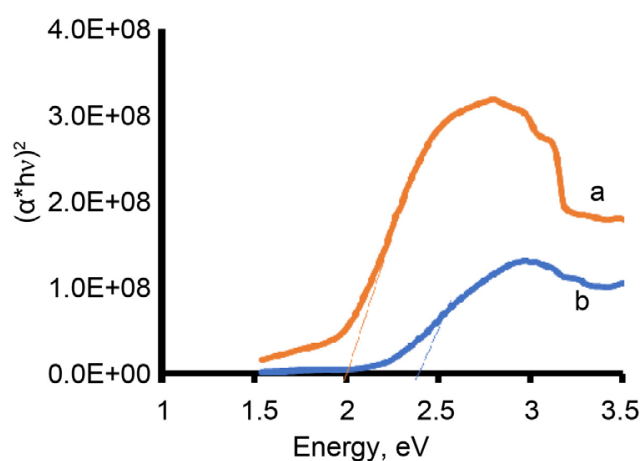

(C)

Figure 1. (A) Absorption spectra (B) $\alpha^{1 / 2}\left(\mathrm{~cm}^{-1 / 2}\right)$ vs photon energy $(\mathrm{C})\left(\alpha^{\star} h v\right)^{2},(\mathrm{eV} \cdot \mathrm{cm})^{2}$ vs photon energy for (a) PBTh and (b) $\mathrm{TiO}_{2} / \mathrm{PThA} / \mathrm{PBTh}$.

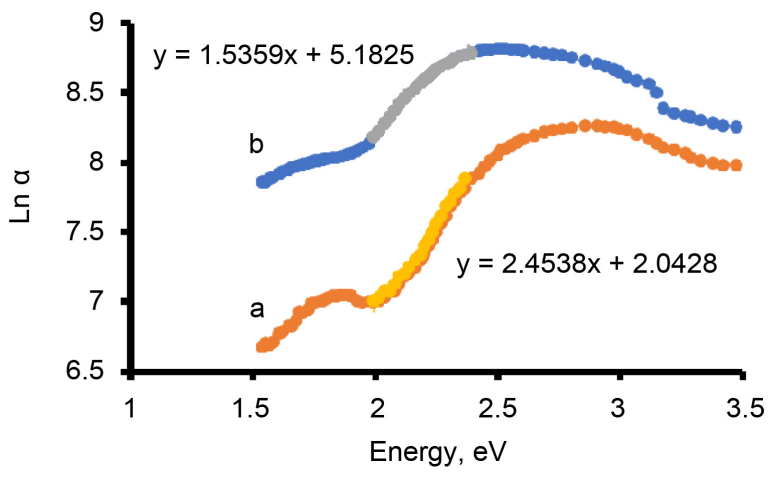

Figure 2. Plot of $\operatorname{Ln} \alpha$ vs photon energy for (a) PBTh and (b) $\mathrm{TiO}_{2} / \mathrm{PThA} / \mathrm{PBTh}$.

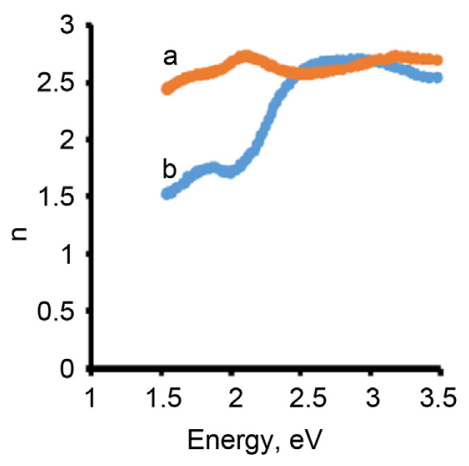

(A)

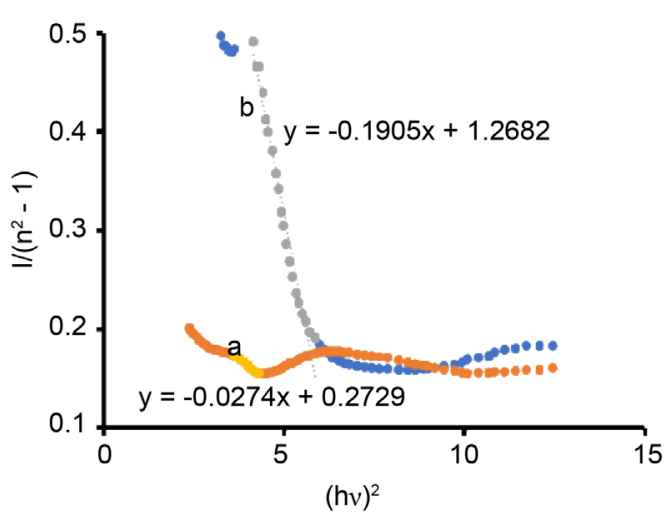

(B)

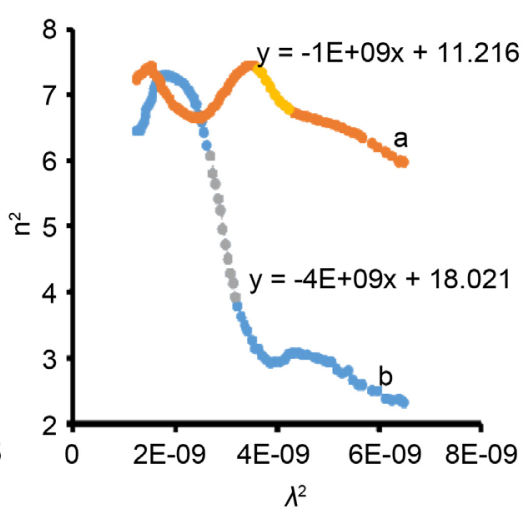

(C)

Figure 3. (A) Refractive index $n$ vs photon energy, (B) $1 /\left(n^{2}-1\right)$ vs $(h v)^{2}$, and (C) $n^{2}$ vs $\lambda^{2}$ for (a) PBTh and (b) $\mathrm{TiO}_{2} / \mathrm{PThA} / \mathrm{PBTh}$.

orbitals (LUMO) of the host polymer. Results shown in Figure 1 also indicate existence of absorption band tails attributed to energy band tail, also known as Urbach energy [29].

Figure 2 shows the plot of $\ln \alpha$ vs photon energy for the host polymer and for the assembly. The rising linear portion of the plot (indicated by colors) exhibits slopes of 1.536 and 2.454 for the assembly and the host respectively. These values 


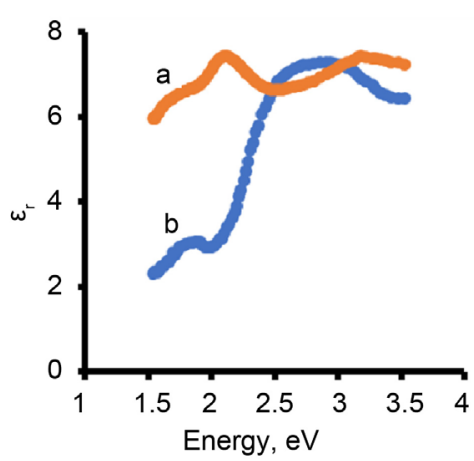

(A)

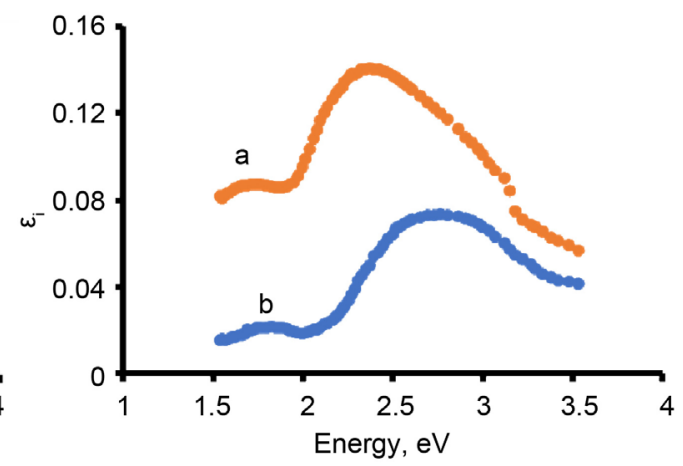

(B)

Figure 4. (A) Real $\varepsilon_{r}$, and (B) imaginary $\varepsilon_{i}$ components of dielectric constant for (a) PBTh and (b) $\mathrm{TiO}_{2} / \mathrm{PThA} / \mathrm{PBTh}$.

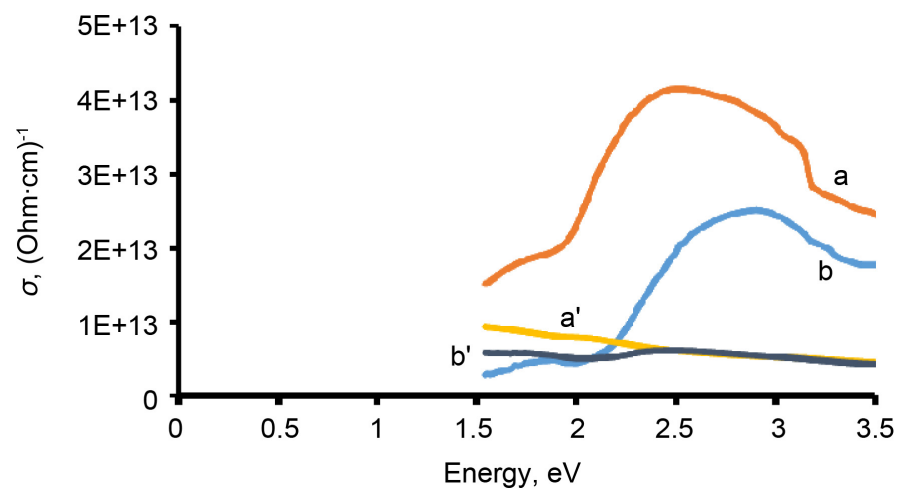

Figure 5. Conductivity (optical $\sigma_{\text {opt }} \&$ electrical $\sigma_{\text {ele }}$ ) vs photon energy, (a) $\sigma_{o p t}$ and, (a') $\sigma_{\text {ele }}$ for PBTh, and (b) $\sigma_{\text {opt }}$ and (b') $\sigma_{\text {ele }}$ for $\mathrm{TiO}_{2} / \mathrm{PThA} / \mathrm{PBTh}$.

correspond to Urbach energy (energy band tail) values of $0.651 \mathrm{eV}$ and $0.407 \mathrm{eV}$ for the assembly and for the host PBTh, respectively. These value of energy band tail reflects the amorphous nature of the material; the greater the energy band tail, the greater the amorphous nature of the material. This indicates that occlusion of $\mathrm{TiO}_{2}$ modified particles into PBTh increased the degree of amorphousness of the assembly.

\subsubsection{Optical Parameters}

1) Refractive index, $n$

Figure 3(A) displays the plot of refractive index (n) vs photon energy. Although both materials exhibit a large increase in $n$ when the photon's energy is greater than $2.0 \mathrm{eV}$, the value of $n$ for $\mathrm{TiO}_{2} / \mathrm{PThA} / \mathrm{PBTh}$ is smaller than that of PBTh up to $\approx 2.5 \mathrm{eV}$, after which both $n$ values are approximately equivalent. Figure 3(A) shows that both $\mathrm{PBTh}$ and $\mathrm{TiO}_{2} / \mathrm{PThA} / \mathrm{PBTh}$ exhibits a normal dispersion region up to $2 \mathrm{eV}$ or at $\lambda 620 \mathrm{~nm}$. At this region, both systems obey a single oscillator model. At $\lambda$ shorter than $620 \mathrm{~nm}$, an anomalous dispersion (multi-oscillator model) can be applied.

At region of normal dispersion, the following equation can be applied [30]: 


$$
\left[n^{2}(h v)-1\right]^{-1}=\frac{-1}{E_{o} E_{d}}(h v)^{2}+\frac{E_{o}}{E_{d}}
$$

where $E_{o}$ is oscillator energy, and $E_{d}$ is the dispersion energy. Plotting the values of $1 /\left(n^{2}-1\right)$ vs $(h v)^{2}$ in the region of single oscillator model, the values of $E_{o}$ and $E_{d}$ can be obtained from the slope and the intercept of the obtained line. Figure 3(B) displays the plots for both $\mathrm{PBTh}$ and $\mathrm{TiO}_{2} / \mathrm{PThA} / \mathrm{PBTh}$. The calculated $E_{o}$ and $E_{d}$ values for PBTh are 3.179 and $11.65 \mathrm{eV}$, respectively, while $E_{o}$ and $E_{d}$ for $\mathrm{TiO}_{2} / \mathrm{PThA} / \mathrm{PBTh}$ are 2.58 and $2.035 \mathrm{eV}$ respectively. As $E_{d}$ is a measure of the inter band intensity, it can be concluded that occlusion of $\mathrm{TiO}_{2} / \mathrm{PThA}$ into $\mathrm{PBTh}$ reduced this intensity evident from the lower $E_{d}$ of $\mathrm{TiO}_{2} / \mathrm{PThA} / \mathrm{PBTh}$ than that of PBTh.

Figure 3(C) was created following the relation [31]:

$$
n^{2}=\varepsilon_{L}-\left[\frac{e^{2}}{\Pi C^{2}}\right]\left[\frac{N}{m^{*}}\right] \lambda^{2}
$$

The intercepts of the linear equations displayed in the Figure 3(C) denote to $\varepsilon_{L}$ lattice dielectric constant. These intercepts are 11.216 and 18.021 for PBTh and for $\mathrm{TiO}_{2} / \mathrm{PThA} / \mathrm{PBTh}$, respectively. This indicates that occlusion of $\mathrm{TiO}_{2} / \mathrm{PThA}$ into PBTh increased the lattice dielectric constant.

2) Dielectric constants, real $\varepsilon_{r}$, and imaginary $\varepsilon_{i}$

Figure 4 displays the plots of the calculated $\varepsilon_{r}$ and $\varepsilon_{i}$ against photon energy. The plot of the $\varepsilon_{r}$ vs photon energy is displayed in Figure 4(A). This figure shows a pattern similar to that displayed in Figure $3(\mathrm{~A})$. As $\varepsilon_{r}$ was calculated from the relation $\varepsilon_{r}=n^{2}-k^{2}$, and as $n \gg k$, we can approximate that $\varepsilon_{r}$ is directly proportional to $n$. On the other hand, Figure $3(\mathrm{~B})$ shows the change in $\varepsilon_{i}$ vs photon energy. It can be noticed that $\varepsilon_{i}$ for the host polymer is greater than that of the hybrid assembly. The $\varepsilon_{i}$ started increasing around the absorption edge and reach its maximum value when photon energy reached $\approx 2.5 \mathrm{eV}$ for $\mathrm{PBTh}$, and about $2.8 \mathrm{eV}$ for $\mathrm{TiO}_{2} / \mathrm{PThA} / \mathrm{PBTh}$.

The results displayed in Figure $4(\mathrm{~A})$ show that the $\varepsilon_{r}$ of PBTh and that of $\mathrm{TiO}_{2} / \mathrm{PThA} / \mathrm{PBTh}$ assembly have closer values around a photon energy range between 2.2 to $3.0 \mathrm{eV}$. Above and below this range the real dielectric part for $\mathrm{TiO}_{2} / \mathrm{PThA} / \mathrm{PBTh}$ was less than that of PBTh. As the real part of the dielectric is related to polarization and anomalous dispersion, the $\varepsilon_{r}$ indicates how much occlusion of $\mathrm{TiO}_{2} / \mathrm{PThA} / \mathrm{PBTh}$ enhanced the speed of light in the material [32].

The results displayed in Figure 4(B) show that: the $\varepsilon_{i}$ of $\mathrm{TiO}_{2} / \mathrm{PThA} / \mathrm{PBTh}$ assembly is less than that calculated for the host polymer PBTh. Such behavior can be explained considering that the $\mathrm{TiO}_{2} / \mathrm{PThA}$ nanoparticles occluded into PBTh inhibit the energy dissipation process [33]. Because $\varepsilon_{i}$ is associated with dissipation of energy into the medium, the $\varepsilon_{i}$ signifies the influence of dipole motion on energy absorption by the dielectric material from an electric field.

3) Optical conductivity $\sigma_{o p t}$ and Electrical conductivity $\sigma_{\text {ele }}$ 
Both $\sigma_{o p t}$ and $\sigma_{\text {ele }}$ were calculated using the following formulas [34] [35] [36]:

$$
\sigma_{\text {opt }}=\frac{\alpha n c}{4 \Pi}
$$

and

$$
\sigma_{e l e}=\frac{2 \lambda \sigma_{o p t}}{\alpha}
$$

The plots of $\sigma_{\text {opt }}$ and $\sigma_{\text {ele }}$ vs photon energy for PBTh and for $\mathrm{TiO}_{2} / \mathrm{PThA} / \mathrm{PBTh}$ is displayed in Figure 5.

Figure 5 clearly shows that 1) $\sigma_{\text {opt }}$ for PBTh is greater than that of $\mathrm{TiO}_{2} / \mathrm{PThA} /$ PBTh, 2) $\sigma_{\text {opt }}$ increases with increasing photon energy up to $2.5 \mathrm{eV}$ for PBTh, and up to $3.0 \mathrm{eV}$ for CdS/PThA/PBTh. The lower optical conductivity of $\mathrm{TiO}_{2} / \mathrm{PThA} / \mathrm{PBTh}$ than $\mathrm{PBTh}$ is due to the presence of modified $\mathrm{TiO}_{2} / \mathrm{PThA}$ nanoparticles as a dopant in PBTh network structure. Figure 5(B) indicates that the dopant lacks the ability to provide the host polymer with an additional charge transfer [34]. Incident light interacts with charges of the material as a result of absorption of photon energy by the assembly. The presence of $\mathrm{TiO}_{2} / \mathrm{PThA}$ impeded the charge polarization process of the material. This means that the $\mathrm{TiO}_{2} / \mathrm{PThA} / \mathrm{PBTh}$ negatively affected the dissipation of energy into the host PBTh film. This is consistent with the results displayed for the $\varepsilon_{i}$ vs photon energy displayed in Figure 4(B). Figure 5(a') and Figure 5(b'), also shows that $\sigma_{e l e}$ for each of $\mathrm{PBTh}$, and for $\mathrm{TiO}_{2} / \mathrm{PThA} / \mathrm{PBTh}$ are smaller than the corresponding $\sigma_{\text {opt }}$ However, they increase slightly with decreasing the photo energy. Such behavior can be explained on the bases of the Drude model [37]. As electrical conductivity is considered as optical conductivity in a lack of alternating field (frequency), at lower photon energy optical conductivity will be under lower frequency.

\subsection{Photoelectrochemical Behavior}

The previous investigation done on the host polymer PBTh [27] was used to compare and drive conclusion on the contribution of the occluded $\mathrm{TiO}_{2} / \mathrm{PThA}$ to the photo activity outcome of the $\mathrm{TiO}_{2} / \mathrm{PThA} / \mathrm{PBTh}$ assembly. Unless otherwise noted, the photoelectrochemical behavior was investigated in the dark and under illumination by cycling the potential of $\mathrm{FTO} / \mathrm{TiO}_{2} / \mathrm{PThA} / \mathrm{PBTh}$ between -1.0 to $1.0 \mathrm{~V}$ vs. $\mathrm{Ag} / \mathrm{AgCl}$ at a scan rate of $0.10 \mathrm{~V} / \mathrm{s}$ in a given electrolyte. The electrode surface area was kept at $2.0 \mathrm{~cm}^{2}$.

\subsubsection{Electrochemical Behavior of the $\mathrm{TiO}_{2} / \mathrm{PThA} / \mathrm{PBTh}$ Assembly in Aqueous Acetate Electrolyte}

The behavior of the $\mathrm{FTO} / \mathrm{TiO}_{2} / \mathrm{PThA} / \mathrm{PBTh}$ assemblies was investigated in $0.2 \mathrm{M}$ acetate electrolyte $(\mathrm{pH} 8)$. Figure 6(A) shows that the recorded photocurrent is greater than the current recorded in the dark in the cathodic scan at $\approx 0.30$ vs $\mathrm{Ag} / \mathrm{AgCl}$. This means that the approximate $E_{f b}$ (flat band potential) of the assembly is at $\approx 0.30 \mathrm{~V}$ or $0.50 \mathrm{~V}$ vs SHE. (Table 1 ). The photocurrent-time 


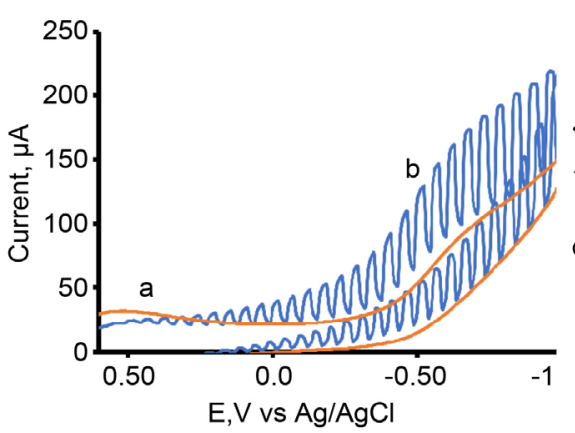

(A)

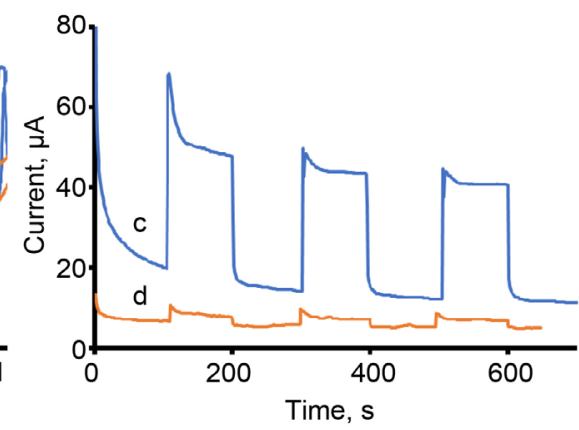

(B)

Figure 6. Photoelectrochemical behavior of $\mathrm{TiO}_{2} / \mathrm{PThA} / \mathrm{PBTh}$ in $0.2 \mathrm{M}$ acetate electrolyte (A) CV at $0.1 \mathrm{~V} / \mathrm{s}$, in (a) dark (b) illumination; (B) Photocurrent vs time curve at $-0.5 \mathrm{~V}$ vs $\mathrm{Ag} / \mathrm{AgCl}$ (c) in the presence of $\mathrm{O}_{2}$, (d) after purge with $\mathrm{N}_{2}$.

Table 1. Photoelectochemical data for the $\mathrm{TiO}_{2} / \mathrm{PThA} / \mathrm{PBTh}$.

\begin{tabular}{ccccc}
\hline Property & $\mathrm{PBTh}$ & $\mathrm{TiO}_{2} / \mathrm{PThA} / \mathrm{PThA}$ & $\mathrm{PThA}$ & $\mathrm{TiO}_{2}$ \\
\hline $\mathrm{IP}, \mathrm{EV}$ & 5.6 & 5.6 & 5.28 & 7.40 \\
$E_{g}, \mathrm{eV}$ & 2.55 & 2.80 & 2.40 & 3.10 \\
$\mathrm{EA}$ & 3.05 & 2.8 & $\approx 2.90$ & 4.30 \\
$E_{f} \mathrm{eV}$ & 5.40 & $\approx 5.4$ & 5.00 & Doping Depend \\
\hline
\end{tabular}

IP = ionization potential, $E_{g}=$ band gap, EA = electron affinity.

curve displayed in Figure 6(B-c), Figure 6(B-d) was generated by subjecting the FTO/CdS/PThA/PBTh assembly to illumination at constant potential $(-0.5$ $\mathrm{V}$ vs $\mathrm{Ag} / \mathrm{AgCl}$ ). Upon illumination of an oxygenated electrolyte, a sharp current spear shown in the first trail followed by steady small changes for longer time Figure 6(B-c). This behavior was reproducible but with a smaller magnitude in the following trials. Such behavior is indication of fast charge recombination due to hole accumulations at the outermost layers of the assembly/electrolyte interface [38]. When the experiment was repeated in deoxygenated electrolyte (using $\mathrm{N}_{2}$ gas), the illumination generated much less photocurrent (Figure 6(B-d)). Figure 6(B) also shows a reduction in the capacitive current in the deoxygenated electrolyte compare to that in presence of oxygen. These results assume that $\mathrm{O}_{2}$ plays an important role in enhancing charge separation during the illumination period.

\subsubsection{Electrochemical Behavior of the $\mathrm{TiO}_{2} / \mathrm{PThA} / \mathrm{PBTh}$ Assembly in Aqueous Citrate Electrolytes}

Figure 7 displays the electrochemical behavior of $\mathrm{FTO} / \mathrm{TiO}_{2} / \mathrm{PThA} / \mathrm{PBTh}$ in aqueous citrate electrolyte ( $\mathrm{pH}$ ) . This figure shows that at $\approx 0.5 \mathrm{~V}$ vs $\mathrm{Ag} / \mathrm{AgCl}$, the photocurrent exceeds the current recorded in the dark for citrate electrolyte (Figure $7(\mathrm{~A})$ ) in the cathodic scan, we assume that the value of the hybrid sub-band is at $\approx 0.7 \mathrm{~V}$ vs SHE.

The photocurrent vs time curve in Figure 7 (B) shows a behavior comparable to that observed in Figure 6(B) (acetate electrolyte). However, upon illumination 


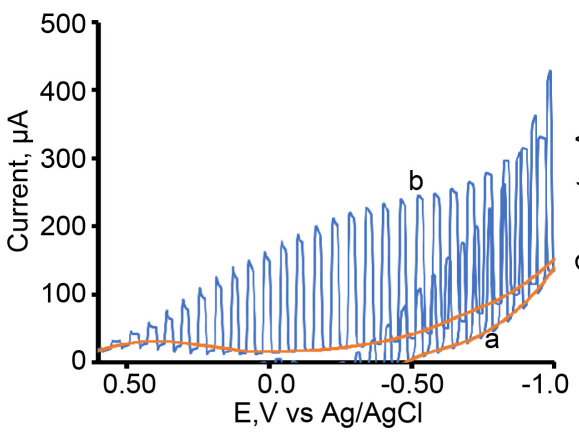

(A)

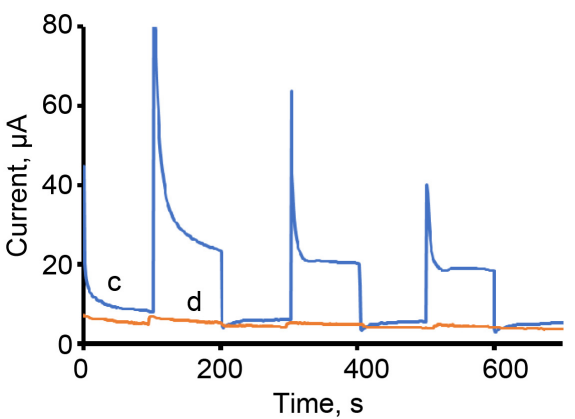

(B)

Figure 7. Photoelectrochemical behavior of $\mathrm{FTO} / \mathrm{TiO}_{2} / \mathrm{PThA} / \mathrm{PBTh}$ in $0.2 \mathrm{M}$ Citrate electrolyte ( $\mathrm{pH}$ 8) (A) $\mathrm{CV}$ at $0.1 \mathrm{~V} / \mathrm{s}$ a) dark, (b) illumination; (B) Photocurrent vs time curve at $-0.5 \mathrm{~V}$ vs $\mathrm{Ag} / \mathrm{AgCl}(\mathrm{c})$ in the presence of $\mathrm{O}_{2}$, and (d) after purge with $\mathrm{N}_{2}$.

of the oxygenated citrate electrolyte (Figure $7(B)$ ), a reproducible larger sharp anodic current spear is observed. Such phenomena were more noticeable in the deoxygenated electrolyte (Figure 7(B-b)). When the light is off there is evidence for reversed transient current, as evident by the small cathodic current spike at the first few seconds in dark. This is due to backflow of electrons from the substrate FTO to the assembly body.

When the electrolyte was deoxygenated, illumination generated much less photocurrent. This behavior was reproducible through multiple cycles of illumination and darkness. The photocurrent generated in citrate is greater than that generated in acetate.

\subsubsection{Electrochemical Behavior of the $\mathrm{TiO}_{2} / \mathrm{PThA} / \mathrm{PBTh}$ Assembly in Aqueous Phosphate Electrolyte}

Figure 8 displays the electrochemical behavior of $\mathrm{TiO}_{2} / \mathrm{PThA} / \mathrm{PBTh}$ in $0.2 \mathrm{M}$ phosphate electrolyte ( $\mathrm{pH} 6$ ) in dark and under illumination. Figure $8(\mathrm{~A})$ shows that at $\approx 0.4 \mathrm{~V}$ vs $\mathrm{Ag} / \mathrm{AgCl}(0.6 \mathrm{~V}$ vs $\mathrm{SHE})$, the recorded photocurrent exceeds that measured in the dark during the cathodic scan. The manual chopping of light experiment indicates that the assembly is highly responsive to the illumination-dark cycles. Furthermore, Figure 8(B) shows the photocurrent-time curve under a constant potential ( $\mathrm{ca}-0.500 \mathrm{~V}$ vs $\mathrm{Ag} / \mathrm{AgCl}$ ) with illumination for a longer period of time. Upon illumination in the oxygenated phosphate electrolyte (Figure 8(B-c)), a sharp anodic current spike, similar to that observed in the citrate was obtained. In darkness, there is no evidence for reversed transient current. This means that no backflow of electrons from the substrate FTO to the assembly body took place. When the electrolyte was deoxygenated using nitrogen gas (Figure $8(B-d)$ ), much less photocurrent was recorded with behavior similar to that observed in the oxygenated solution.

Upon illumination of the oxygenated phosphate electrolyte (Figure 8(B-a)), a sudden increase in the photocurrent was recorded followed by a steady decrease in photocurrent to constant quantity. The initial decay reflects some e/h recombination. The photocurrent vs time curve for the host polymer PBTh only [27] is 


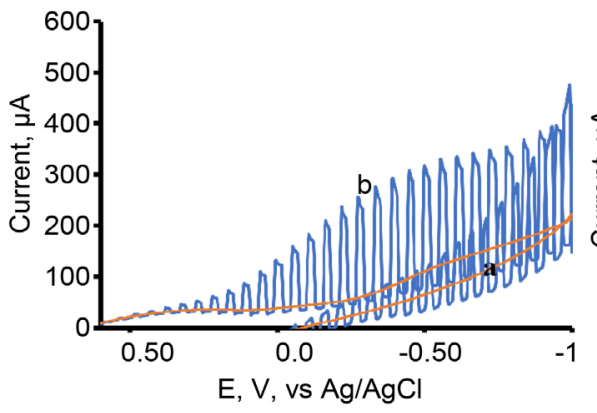

(A)

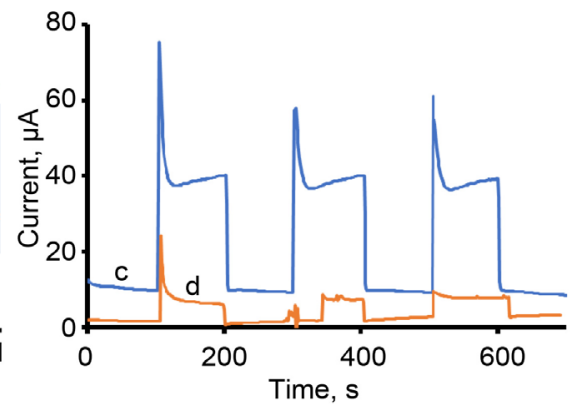

(B)

Figure 8. Photoelectrochemical behavior of $\mathrm{TiO}_{2} / \mathrm{PThA} / \mathrm{PBTh}$ in $0.2 \mathrm{M}$ phosphate electrolyte ( $\mathrm{pH}$ 6). (A) $\mathrm{CV}$ at $0.1 \mathrm{~V} / \mathrm{s}$ (a) dark, (b) illumination; (B) Photocurrent vs time curve at $-0.5 \mathrm{~V}$ vs $\mathrm{Ag} / \mathrm{AgCl}(\mathrm{c})$ in the presence of $\mathrm{O}_{2}$, and (d) after purge with $\mathrm{N}_{2}$.

smaller than that observed in Figure 8(B). This indicates that occlusion of $\mathrm{TiO}_{2}$ enhanced the photocurrent generation as a result of improvement of the photo-induced charge separation.

We further investigated the effect of changing the $\mathrm{pH}$ on the $E_{f b}$ of this assembly. No changes in $E_{f b}$ were observed within the $\mathrm{pH} 5$ - 8 range. A change of approximate $2 \mathrm{pH}$ units did not affect the position of $E_{F b}$ in the sulfur-based assembly. The relation between $E_{F b}$ and $\mathrm{pH}$ in oxide-based semiconductors, changes by $25 \mathrm{mV}$ per change in $1 \mathrm{pH}$ unit.

Oxygen involvement in the photochemical activities is in the electron consummation processes illustrated by the equation:

$$
\mathrm{O}_{2}+2 \mathrm{e}+2 \mathrm{H}^{+} \rightarrow \mathrm{H}_{2} \mathrm{O}_{2}
$$

As PBTh act as p-type semiconductor where holes are the charge carrier. When the outermost layer of the assembly is hit by suitable photon energy, this creates a shorter diffusion course to photogenerated holes to reach the adsorbed anions on the surface of the assembly. This makes the hole consummation by the used electrolytes anions is important step in the mechanism of charge separation.

The following explains the oxidation of the studied anions at the electrolyte $\mathrm{TiO}_{2} / \mathrm{PThA} / \mathrm{PBTh} /$ electrolyte interface.

For oxidation of phosphate anion, a formation of phosphate radical anion [39] can prevent the $\mathrm{e} / \mathrm{h}$ recombination process according to Equation (6),

$$
\mathrm{HPO}_{4}^{2-} \text { (aq) }+\mathrm{h} \rightarrow \mathrm{HPO}_{4(\text { aq })}^{-}
$$

Involvement of both oxygen and phosphate in the charge separation process that lowers the e/h recombination is explained by Equations (5) and (6).

In case of carboxylic anions, a Kolb-type reaction [40] causes photooxidation of carboxylate anions according to the following equation:

$$
\mathrm{R}\left(\mathrm{COO}^{-}\right)_{(\mathrm{aq})}+\mathrm{h} \rightarrow \mathrm{R}_{(\text {(aq) }}+\mathrm{CO}_{2(\mathrm{gas})}
$$

\subsubsection{Electrochemical Impedance Spectroscopic Studies}

Impedance spectra of the $\mathrm{FTO} / \mathrm{TiO}_{2} / \mathrm{PThA} /$ or $\mathrm{FTO} / \mathrm{PBTh}$ was measured and 
analyzed on three-electrode cell containing liquid electrolytes, between $10^{5}-10^{-2}$ $\mathrm{Hz}$ utilizing Solartron 1201A, MX-studio ECS software. Impedance complexes (Nyquist plot) generated from these studies are displayed in Figure 9. This Figure shows both kinetic control at high frequency and diffusional control at low frequency. The shape of unconcentrated semicircle in at high frequencies and existence of Warburg impedance reflects the film porosity [41]. The calculated $C_{d l}$ was $7.43 \times 10^{-5} \mathrm{~F}$. The maxima of the semicircle corresponded to relaxation frequency of $1.25 \mathrm{~Hz}$, which is $0.79 \mathrm{~s}$ relaxation time.

Using equivalent circuit and modeling approach by Randel [42], the reaction rate at the assembly interface can be calculated. The difference between $R_{c t}$ and the intercepts of the tangent line of Warburg diffusional region equals to [ $R_{c t} \times$ $\left.\lambda)^{2} \times C_{d l}\right]$, where $\lambda=\frac{k}{\sqrt{D}}, k$ is rate constant, and $D$ is the diffusion coefficient. Knowing $(\lambda)$ and $D, k$ can be calculated For Warburg frequency region (the very low frequencies), plotting the $Z^{\prime \prime}$ vs $1 / \omega$ (Figure 9 inset) generates a straight line with slop $\left.=1 / C_{L}\right)=191 \mathrm{~F}^{-1}$. Substituting the approximate $R_{L}$ value of $5000 \mathrm{ohm}$, the diffusion coefficient can be determined using the following equation:

$$
R_{L}=\frac{1}{C_{L}} * \frac{L^{2}}{3 D_{C T}}
$$

For $L=1 \mu \mathrm{m}$, the calculated $D$ was $=5.65 \times 10^{-10} \mathrm{~cm}^{2} / \mathrm{s}$. The calculated $k$ under dark condition is $1.89 \times 10^{-5} \mathrm{~cm} / \mathrm{s}$, while under illumination $k$ is $2.22 \times 10^{-5}$ $\mathrm{cm} / \mathrm{s}$.

1) Dielectric constants

Figure 10 Shows that dielectric constants increased at very low frequencies. As frequency increased, the values of the dielectric constants decreased. Such

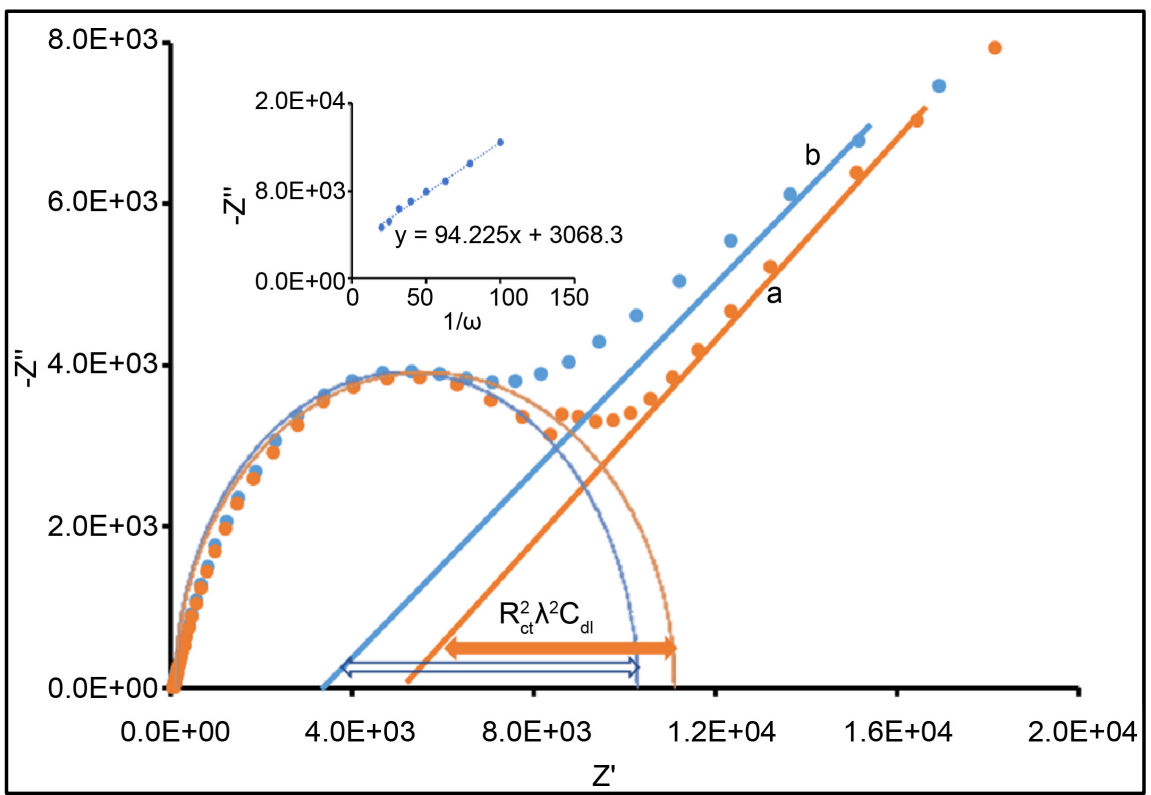

Figure 9. Nyquist plot of $3 \mu \mathrm{m}, \mathrm{TiO}_{2} / \mathrm{PThA} / \mathrm{PBTh}$ film on FTO in $0.2 \mathrm{M}$ acetate electrolytes (pH 6) at $0.5 \mathrm{~V} \mathrm{vs} \mathrm{Ag} / \mathrm{AgCl}$ (a) dark, (b) light. 


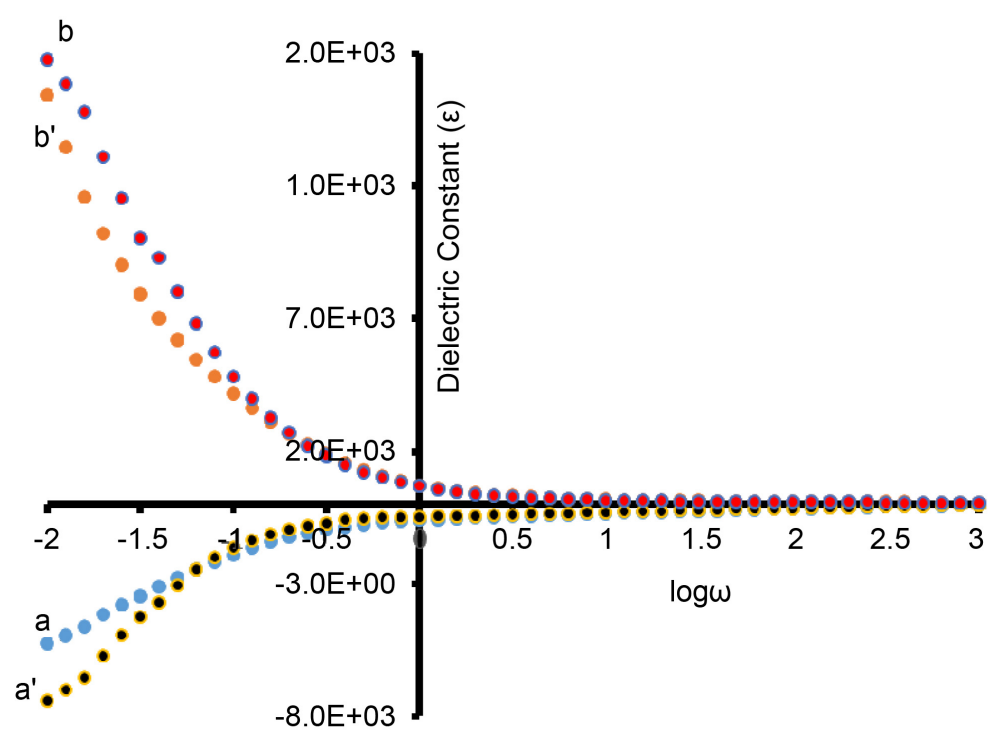

Figure 10. Plot of dielectric constant $\varepsilon$ vs $\log \omega$ (a) real dielectric component $\left(\varepsilon_{r}\right)$, and (b) imaginary component $\left(\varepsilon_{i}\right)$ under illumination, $\left(\mathrm{a}^{\prime}\right) \varepsilon_{r}$ and $\left(\mathrm{b}^{\prime}\right) \varepsilon_{p}$ in dark, in acetate electrolyte ( $\mathrm{pH} 8)$.

behavior was previously observed and attributed to the inability of the electric dipoles to comply with variation of an applied a.c. electric field [43]. Materials that possess conducting grains, but with poor conducting boarders causes charge carriers accumulated at these boarders, when external external electric field (low frequency) is applied. This creates large polarization and consequently a high dielectric constant [44].

2) AC conductivity $\sigma_{a c}$

The $\sigma_{a c}$ was calculated using the following equation [45].

$$
\sigma_{a c}=\frac{L}{A} * \frac{Z^{\prime}}{Z^{\prime 2}+Z^{\prime 2}}
$$

According to the following equation [46]:

$$
\sigma_{a c}=\sigma_{d c}+A \omega^{S}
$$

where $A$ is the strength of polarizability, $s$ is temperature dependent parameter which can be determined from the slope of line of the plot of $\log \sigma_{a c} v s \log \omega$.

$$
\log \sigma_{a c}=\log \sigma_{d c}+\log A+S \log \omega
$$

Figure 11 was constructed to show the plot of calculated $\log \sigma_{a c}$ vs $\log \omega$ at different frequencies. This figure clearly shows the positive correlation between $\sigma_{a c}$ and $\omega$ at the high dispersive region of high frequencies range up to several $\mathrm{kHz}$. The slope of the line ( $\mathrm{s}$ ) was $=0.7901$, which indicates the hopping due to the translational motion [47]. Figure 11 also shows that the conductivity at very low frequency (ca $10^{-2} \mathrm{~Hz}$ ) which is corresponds to $\sigma_{d c}$ and it is much smaller than $\sigma_{a c}$ The energy required to remove one electron from one site to another within the film structure $\left(W_{m}\right)$ or binding energy, can be calculated from the following relation [48]: 


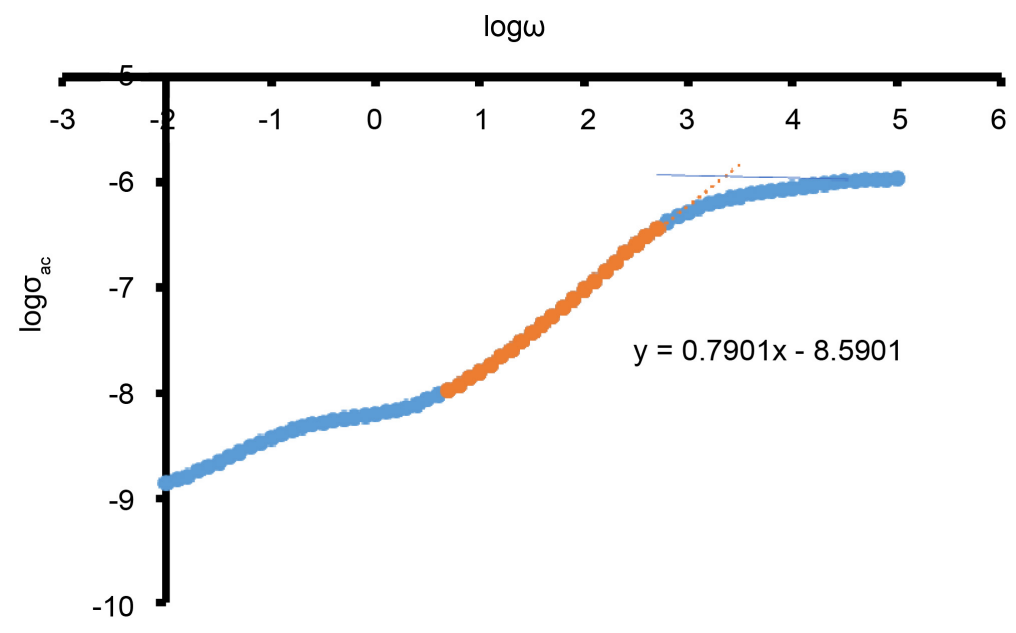

Figure 11. $\log \sigma_{a c}$ vs $\log \omega$ for $\mathrm{TiO}_{2} / \mathrm{PThA} / \mathrm{PBTh} / \mathrm{FTO}$ in acetate electrolyte (pH 6) at $298 \mathrm{~K}$, in dark.

$$
W_{m}=\frac{6 k_{B} T}{1-S}
$$

The obtained s value is corresponding to $W_{m}$ of $1.233 \times 10^{-19} \mathrm{~J}$ or $0.76 \mathrm{eV}$. The minimum hopping distance $R_{\min }$ can be calculated as follow [48]:

$$
R_{\min }=\frac{2 e^{2}}{\pi \varepsilon \varepsilon_{o} W_{m}}
$$

The hopping distance $R_{\min }$ corresponding to the calculated $W_{m}$ is $15 \mathrm{~nm}$. Both $W_{m}$ and $R_{\min }$ are temperature dependent, they generally decreases as temperature increases if $s$ decreases with increasing temperature. The data plotted in Figure 11 were closer to those reported under illumination. No change in $s$ value was reported.

\subsection{Band-Energy Map of $\mathrm{TiO}_{2} / \mathrm{PThA} / \mathrm{PBTh}$}

Mott-Schottky plot of $\mathrm{TiO}_{2} / \mathrm{PThA} / \mathrm{PBTh}$ in acetate electrolyte was generated using $1 \mathrm{KHz}$ with a sinusoidal signal of $10 \mathrm{mV}$ peak to peak amplitude (Figure 12). The slope indicates a carrier density (holes) $N_{D}=2.93 \times 10^{19}$. The intercept indicates the position of flat band potential $\left(E_{f}\right)$ at $0.40 \mathrm{~V}$ vs $\mathrm{Ag} / \mathrm{AgCl}$ or at $5.4 \mathrm{eV}$ on vacuum scale. In similar studies on the host film PBTh, the value for $\mathrm{N}_{D}$ was $9.67 \times 10^{19}$, with no changes in $E_{f}$ values. This indicates that the only change that occlusion of $\mathrm{TiO}_{2} / \mathrm{PThA}$ in PBTh caused was a lowering of the carrier density. Closer look at the CV's displayed in Figures 6-8, the current recorded upon illumination exceeds that recorded in dark at $\approx 0.4 \mathrm{~V}$ vs $\mathrm{Ag} / \mathrm{AgCl}$ or at $\approx 0.6 \mathrm{~V}$ vs SHE. This potential was assumed to be $E_{f}$ and it is confirmed by Mott-Schottky plot. This also indicates that $E_{f}$ did not change by changing the electrolyte.

The data listed in Table 1 were used to generate an energy map displayed in Figure 13. This figure illustrates the formation of a hybrid sub-band energy level that organizes the charge transfer at the $\mathrm{TiO}_{2} / \mathrm{PThA} / \mathrm{PBTh}$. Hybridization between hole-like and electron-like sub-band states takes place in close proximity 


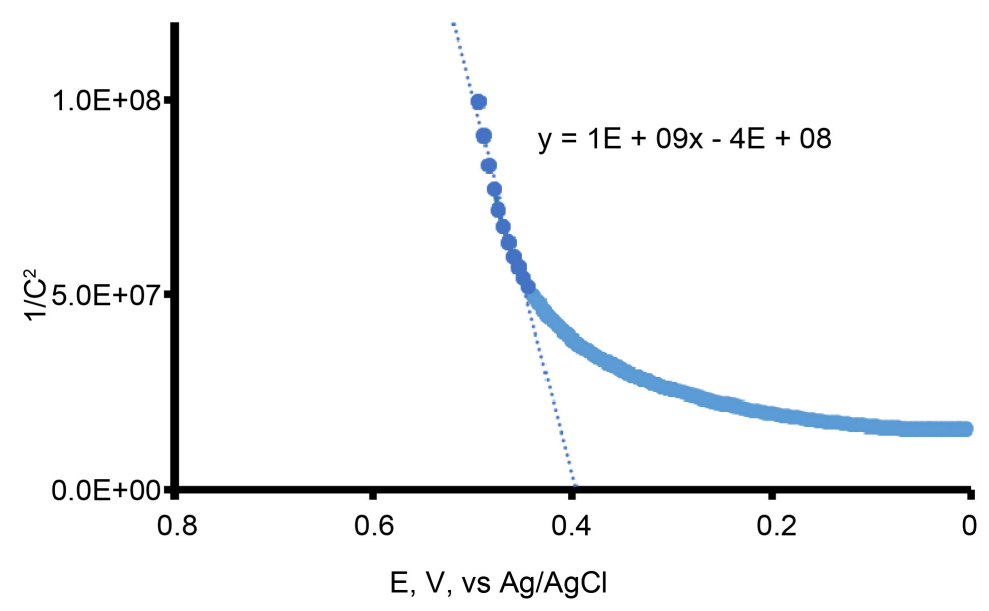

Figure 12. Mott Schuttky plot of $\mathrm{TiO}_{2} / \mathrm{PThA} / \mathrm{PBTh}$ in $0.2 \mathrm{M}$ acetate electrolyte $\mathrm{pH} 6$.

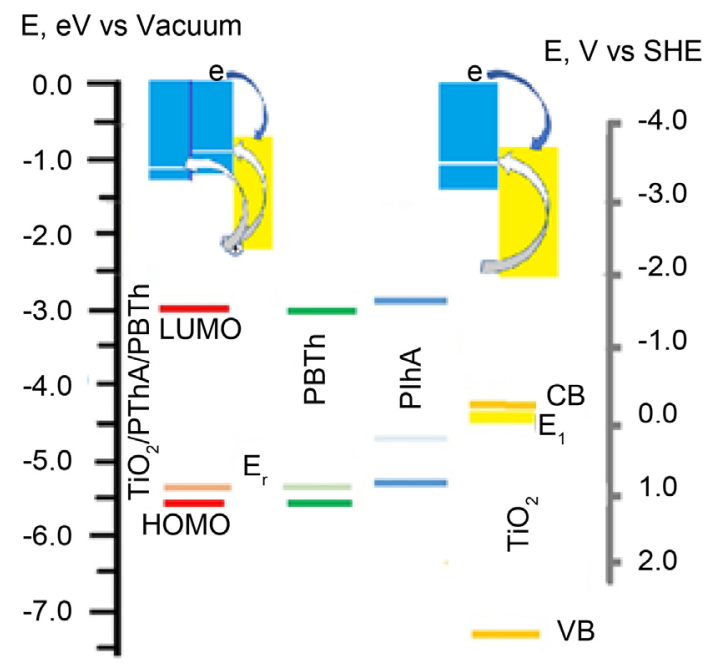

Figure 13. Energy map for $\mathrm{TiO}_{2} / \mathrm{PThA} / \mathrm{PBTh}$ interface.

to the Fermi level. The difference between the energy level of the hybrid band and valance band $(\mathrm{VB})$ represents a hole barrier height of $\mathrm{TiO}_{2}$ being $\sim 2.2 \mathrm{eV}$. That is more negative than the $\mathrm{VB}$ of $\mathrm{TiO}_{2}$. When the magnitude of the hybrid band has more negative potential $(\sim 2.2 \mathrm{~V})$ than $\mathrm{VB}$, attraction to the hole is stronger than at a less negative potential. This makes the charge transfer process via hole transfer more likely. This rule out electrons participation in the charge transfer process. This is because the electron barrier height is $\sim 1.3 \mathrm{eV}$ which is $\sim 1.3 \mathrm{~V}$ more positive than the potential of the electrons in the LUMO of the modifier PThA. At the PThA/TiO ergy level than the LUMO. This causes the electron barrier height to be even lower than the calculated value $(\sim 1.3 \mathrm{eV})$.

\section{Conclusion}

EIS studies revealed that the assembly film of $\mathrm{TiO}_{2} / \mathrm{PThA} / \mathrm{PBTh}$ possesses a 
porous-type structure. It also confirmed the approximate value of $E_{f}$ obtained from electrochemical studies. Guided by the properties of the host PBTh, some optical properties such as $\left(E_{o}\right)$ oscillator energy, and $\left(E_{d}\right)$ dispersion energy, $\sigma_{o p t}$ and $\sigma_{e l e}\left(\equiv \sigma_{d c}\right)$ were calculated. EIS was used to calculate $\sigma_{a c}$ and $\sigma_{d c}$ Both EIS and optical studies indicated that ac conductivity is much greater than dc conductivity. Data listed in Table 1 indicate that no large changes in the energy band structure due to the occlusion of $\mathrm{TiO}_{2}$ in organic films occurs. The fact that the $\sigma_{o p t}$ of the assembly is less than $\sigma_{o p t}$ of PBTh indicates that occlusion of modified $\mathrm{TiO}_{2}$ nanoparticles into the network structure of PBTh; 1) inhibited the energy dissipation process, and 2) impeded charge polarization process of the material. Photoelectrochemical results show that the behavioral outcome of the assemblies was dominated by poly bithiophene. Possible band alignments between the organic film and $\mathrm{TiO}_{2}$ nanoparticles, cause formation of hybrid sub-bands. Furthermore, inclusion of $\mathrm{TiO}_{2}$ in the thiophene-based polymers enhanced the charge separation, and consequently charge transfer processes. The PBTh, PThA, and amorphous $\mathrm{TiO}_{2}$ have band gaps that allow absorption of broad wavelengths in the blue zone which makes both materials and their I/O/O/I assemblies potentially useful in solar energy harvesting systems.

\section{Acknowledgements}

The authors acknowledge Office of the Academic Affairs, at Indiana University Kokomo for supporting this project.

\section{Conflicts of Interest}

The authors declare no conflicts of interest regarding the publication of this paper.

\section{References}

[1] Wei, H., Yan, X., Wu, S., Luo, Z., Wei, S. and Guo, Z. (2012) Electropolymerized Polyaniline Stabilized Tungsten Oxide Nanocomposite Films: Electrochromic Behavior and Electrochemical Energy Storage. The Journal of Physical Chemistry C, 116, 25052-25064. https://doi.org/10.1021/jp3090777

[2] Braun, S., Osikowicz, W., Wang, Y. and Salaneck, W.R. (2007) Energy Level Alignment Regimes at Hybrid Organic-Organic and Inorganic-Organic Interfaces. Organic Electronics, 8, 14-20. https://doi.org/10.1016/j.orgel.2006.10.006

[3] Ananthakumar, S., Ramkumar, J. and Moorthy Babu, S. (2014) Synthesis of Thiol Modified CdSe Nanoparticles/ $\mathrm{P}_{3} \mathrm{HT}$ Blends for Hybrid Solar Cell Structures. Materials Science in Semiconductor Processing, 22, 44-49. https://doi.org/10.1016/j.mssp.2014.02.008

[4] Otero, M., Dittrich, T., Rappich, J., Heredia, D.A., Fungo, F., Durantini, E. and Otero, L. (2015) Photoinduced Charge Separation in Organic-Inorganic Hybrid System: $\mathrm{C}_{60}$-Containing Electropolymer/CdSe-Quantum Dots. Electrochimica Acta, 173, 316-322. https://doi.org/10.1016/j.electacta.2015.05.029

[5] Zhong, Y.F., Akira, T., Geng, Y.F., Wei, Q.S., Kazuhito, H. and Keisuke, T. (2013) Donor/Acceptor Interface Modifications in Organic Solar Cells. Journal of Photo- 
polymer Science and Technology, 26, 181-184.

https://doi.org/10.2494/photopolymer.26.181

[6] Chen, Y.F., Tamblyn, I. and Quek, S.Y. (2017) Energy Level Alignment at Hybridized Organic-Metal Interfaces: The Role of Many-Electron Effects. The Journal of Physical Chemistry C, 121, 13125-13134. https://doi.org/10.1021/acs.jpcc.7b00715

[7] Li, Y., et al. (2015) Enhancing Photoelectrical Performance of Dye-Sensitized Solar Cell by Doping $\mathrm{SrTiO}_{3}: \mathrm{Sm}^{3+} @ \mathrm{SiO}_{2}$ Core-Shell Nanoparticles in the Photoanode. Electrochimica Acta, 173, 656-664. https://doi.org/10.1016/j.electacta.2015.05.116

[8] Rather, R.A., Singh, S. and Pal, B. (2017) A $\mathrm{C}_{3} \mathrm{~N}_{4}$ Surface Passivated Highly Photoactive $\mathrm{Au}-\mathrm{TiO}_{2}$ Tubular Nanostructure for the Efficient $\mathrm{H}_{2}$ Production from Water under Sunlight Irradiation. Applied Catalysis B: Environmental, 213, 9-17. https://doi.org/10.1016/j.apcatb.2017.05.002

[9] Teoh, W.Y., Scott, J.A. and Amal, R. (2012) Progress in Heterogeneous Photocatalysis: From Classical Radical Chemistry to Engineering Nanomaterials and Solar Reactors. The Journal of Physical Chemistry Letters, 3, 629-639. https://doi.org/10.1021/jz3000646

[10] Lee, J.S., You, K.H. and Park, C.B. (2012) Highly Photoactive, Low Bandgap $\mathrm{TiO}_{2}$ Nanoparticles Wrapped by Graphene. Advanced Materials, 24, 1084-1088. https://doi.org/10.1002/adma.201104110

[11] Karandikar, P.R., Lee, Y.-J., Kwak, G., Woo, M.H., Park, S.-J., Park, H.-G., Ha, K.-S. and Jun, K.-W. (2014) $\mathrm{Co}_{3} \mathrm{O}_{4} @$ Mesoporous Silica for Fischer-Tropsch Synthesis: Core-Shell Catalysts with Multiple Core Assembly and Different Pore Diameters of Shell. The Journal of Physical Chemistry C, 118, 21975-21985. https://doi.org/10.1021/jp504936k

[12] Lamberti, A. (2018) $\mathrm{ZnO}$ - and $\mathrm{TiO}_{2}$-Based Nanostructures. Nanomaterials, 8, 325. https://doi.org/10.3390/nano8050325

[13] Singh, R. and Dutta, S. (2018) Synthesis and Characterization of Solar Photoactive $\mathrm{TiO}_{2}$ Nanoparticles with Enhanced Structural and Optical Properties. Advanced Powder Technology, 29, 211-219. https://doi.org/10.1016/j.apt.2017.11.005

[14] González, E., Bonnefond, A., Barrado, M., Barrasa, C., Aurora, M., Asua, J.M. and Leiza, J.R. (2015) Photoactive Self-Cleaning Polymer Coatings by $\mathrm{TiO}_{2}$ Nanoparticle, Pickering Miniemulsion Polymerization. The Chemical Engineering Journal, 281, 209-217.

[15] Gun, Y., Song, G.Y., Quy, V.H.V., Heo, J., Lee, H., Ahn, K.-S. and Kang, S.H. (2015) Joint Effects of Photoactive $\mathrm{TiO}_{2}$ and Fluoride-Doping on $\mathrm{SnO}_{2}$ Inverse Opal Nanoarchitecture for Solar Water Splitting. ACS Applied Materials \& Interfaces, 7, 20292-20303. https://doi.org/10.1021/acsami.5b05914

[16] Villatte, G., et al. (2015) Photoactive $\mathrm{TiO}_{2}$ Antibacterial Coating on Surgical External Fixation Pins for Clinical Application. International Journal of Nanomedicine, 10, 3367-3375. https://doi.org/10.2147/IJN.S81518

[17] Lee, S.-W., Ahn, K.-S., Zhu, K., Neale, N.R. and Frank, A.J. (2012) Effects of $\mathrm{TiCl}_{4}$ Treatment of Nanoporous $\mathrm{TiO}_{2}$ Films on Morphology, Light Harvesting, and Charge-Carrier Dynamics in Dye-Sensitized Solar Cells. The Journal of Physical Chemistry C, 116, 21285-21290. https://doi.org/10.1021/jp3079887

[18] Tunc, I., Bruns, M., Gliemann, H., Grunze, M. and Koelsch, P. (2010) Bandgap Determination and Charge Separation in $\mathrm{Ag} @ \mathrm{TiO}_{2}$ Core Shell Nanoparticle Films. Surface and Interface Analysis, 42, 835-841. https://doi.org/10.1002/sia.3558

[19] Nuño, M., Ball, R.J., Bowen, C.R., Kurchania, R. and Sharma, G. (2015) Photocatalytic Activity of Electrophoretically Deposited (EPD) $\mathrm{TiO}_{2}$ Coatings. Journal of Ma- 
terials Science, 50, 4822-4835. https://doi.org/10.1007/s10853-015-9022-0

[20] Rahman, A., et al. (2015) Surface Modification of Natural Fiber Using $\mathrm{Bi}_{2} \mathrm{O}_{3} / \mathrm{TiO}_{2}$ Composite for Photocatalytic Self-Cleaning. BioResources, 10, 7405-7418. https://doi.org/10.15376/biores.10.4.7405-7418

[21] Keddam, M., Senyarich, S., Takenouti, H. and Bernard, P. (1994) A Composite Electrode for Studying Powdered Electroactive Materials: Preparation and Performance. Journal of Applied Electrochemistry, 24, 1037-1043. https://doi.org/10.1007/BF00241196

[22] Anani, A., Mao, Z., Srinivasan, S. and Appleby, A.J. (1991) Dispersion Deposition of Metal-Particle Composites and the Evaluation of Dispersion Deposited Nickel-Lanthanum Nickelate Electrocatalyst for Hydrogen Evolution. Journal of Applied Electrochemistry, 21, 683-689. https://doi.org/10.1007/BF01034046

[23] Hovestad, A. and Janssen, L.J.J. (1995) Electrochemical Codeposition of Inert Particles in a Metallic Matrix. Journal of Applied Electrochemistry, 25, 519-527. https://doi.org/10.1007/BF00573209

[24] Beck. P., Dahhaus, M. and Zahedi, N.N. (1992) Anodic Codeposition of Polypyrrole and Dispersed $\mathrm{TiO}_{2}$. Electrochimica Acta, 37, 1265-1272. https://doi.org/10.1016/0013-4686(92)85066-T

[25] De Tacconi, N.R., Wenren, H. and Rajeshwar, K. (1997) Photoelectrochemical Behavior of Nanocomposite Films of Cadmium Sulfide, or Titanium Dioxide, and Nickel. Journal of the Electrochemical Society, 144, 3159-3163. https://doi.org/10.1149/1.1837975

[26] Kasem, K., Olsen, J.C., Baker, K., Santucci, C., Lalla, J. and Willman, A.N. (2016) Electrochemical Studies on a Photoactive CdS. Synthetic Metals, 217, 61-67. https://doi.org/10.1016/j.synthmet.2016.03.013

[27] Kasem, K.K., Elmasry, M., Baker, K. and Santucci, C. (2017) Photoelectrochemical and Magnetic Studies on Photoactive Interface Thin Solid Film Assemblies. Thin Solid Films, 634, 56-65. https://doi.org/10.1016/j.tsf.2017.05.016

[28] Tauc, J. (1968) Optical Properties and Electronic Structure of Amorphous Ge and Si. Materials Research Bulletin, 3, 37-46. https://doi.org/10.1016/0025-5408(68)90023-8

[29] Urbach, F. (1953) The Long-Wavelength Edge of Photographic Sensitivity and of the Electronic Absorption of Solids. Physical Review, 92, 1324. https://doi.org/10.1103/PhysRev.92.1324

[30] Wemple, S.H. and DiDomenico, M.D. (1971) Behavior of the Electronic Dielectric Constant in Covalent and Ionic Materials. Physical Review B, 3, 1338-1351.

[31] Kumar, G.A., Thomas, J., George, N., Kumar, B.A., Shnan, P.R., Npoori, V.P., Vallabhan, C.P.G. and Unnikrishnan, N.V. (2001) Optical Absorption Studies of Free $\left(\mathrm{H}_{2} \mathrm{Pc}\right)$ and Rare Earth (RePc) Phthalocyanine Doped Borate Glasses. Physics and Chemistry of Glasses, 41, 89-93.

[32] Wu, M.T., Yao, X., Yuan, Z.H., Sun, H.T., Wu, W.C., Chen, O.H. and Xu, G.Y. (1993) Effect of Noble Metal Catalyst on Titania Exhaust Gas Oxygen Sensor. Sensors and Actuators B, 14, 491. https://doi.org/10.1016/0925-4005(93)85060-N

[33] Dressel, M. (2002) Electrodynamics of Solids Optical Properties of Electrons in Matter. Cambridge University Press, Cambridge, UK.

[34] Pankaj, S. and Katyal, S.C. (2007) Determination of Optical Parameters of alfa $\left(\mathrm{As}_{2} \mathrm{Se}_{3}\right)_{90} \mathrm{Ge}_{10}$ Thin Film. Journal of Physics D: Applied Physics, 40, 2115-2120. https://doi.org/10.1088/0022-3727/40/7/038 
[35] Sabari Girisum, T.C. and Dhanushkodi, S. (2009) Linear and Nonlinear Optical Properties of Tris Thiourea Zincsulphate Single Crystals. Crystal Research and Technology, 44, 1297-1302. https://doi.org/10.1002/crat.200900351

[36] Saranraj, A., Sahaya, S., Jude, D., Vinitha, G. and Martin Britto Dhas, S.A. (2017) Third Harmonic Generation and Thermos-Physical Properties of Benzophenone Single Crystal for Phototonic Applications. Materials Research Express, 4, Article ID: 106204. https://doi.org/10.1088/2053-1591/aa8b7b

[37] Drude, P. (1900) Zur Elektronentheorie der Metalle. Annalen der Physik, 306, 566-613. https://doi.org/10.1002/andp.19003060312

[38] Sookhakian, M., Amin, Y.M., Baradaran, S., Tajabadi, M.T., MoradiGolsheikh, A. and Basirun, W.J. (2014) A Layer-by-Layer Assembled Graphene/Zinc Sulfide/Polypyrrole Thin-Film Electrode via Electrophoretic Deposition for Solar Cells. Thin Solid Films, 552, 204-211. https://doi.org/10.1016/j.tsf.2013.12.019

[39] Mohammad, A., Gary, K.C.L. and Matthews, R.W. (1990) Effects of Common Inorganic Anions on Rates of Photocatalytic Oxidation of Organic Carbon over Illuminated Titanium Dioxide. The Journal of Physical Chemistry, 94, 6820-6825.

[40] Cerviño, R.M., Triaca, W.E. and Arvía, A.J. (1984) Phenomenology Related to the Kinetics of Kolbe Electrosynthesis. Journal of Electroanalytical Chemistry, 172, 255-264. https://doi.org/10.1016/0022-0728(84)80190-4

[41] Kaiser, H., Beccu, K.D. and Gutjahr, M.A. (1976) Abschätzung der porenstruktur poröser elektroden aus impedanzmessungen. Electrochimica Acta, 21, 539-543. https://doi.org/10.1016/0013-4686(76)85147-X

[42] Randel, J.E.B. (1947) Kinetics of Rapid Electrode Reactions. Discussions of the Faraday Society, 1, 11-19. https://doi.org/10.1039/df9470100011

[43] Joshi, J.H., Kanchan, D.K., Joshi, M.J., Jethva, H.G. and Parikh, K.D. (2017) Dielectric Relaxation Complex Impedance and Modulus Spectroscopy. Materials Research Bulletin, 93, 61-73. https://doi.org/10.1016/j.materresbull.2017.04.013

[44] Gopal Reddy, T. and Rajesh Kumar, B. (2011) Structural and Dielectric Properties of Barium Bismuth Titanate $\left(\mathrm{BaBi}_{4} \mathrm{Ti}_{4} \mathrm{O}_{15}\right)$ Ceramics. International Journal of Applied Engineering Research, 6, 571-570.

[45] Joshia, J.H., Kanchan, D.K., Joshi, M.J., Jethva, H.O. and Parikh, K.D. (2017) Dielectric Relaxation, Complex Impedance and Modulus Spectroscopic Studies of Mix Phase Rod Like Cobalt Sulfide Nanoparticles. Materials Research Bulletin, 93, 63-73. https://doi.org/10.1016/j.materresbull.2017.04.013

[46] Jonscher, A.K. (1997) The “Universal” Dielectric Response. Nature, 267, 673-679. https://doi.org/10.1038/267673a0

[47] Funke, K. (1993) Jump Relaxation in Solid Electrolytes. Progress in Solid State Chemistry, 22, 111-195. https://doi.org/10.1016/0079-6786(93)90002-9

[48] Hayat, K., Rafiq, M.A., Durrani, S.K. and Hasan, M.M. (2011) Impedance Spectroscopy and Investigation of Conduction Mechanism in $\mathrm{BaMnO}_{3}$ Nanorods. Physica $B$ Condensed Matter, 406, 309-314. https://doi.org/10.1016/j.physb.2010.09.026 